\title{
ComparaÇão de TéCnicas de Deteç̧ão de Faltas de Alta ImpedânCia em um Sistema Realístico DE Distribuição de ENERgia ElÉTrica
}

\author{
Mauricio de CAmpos $^{1}$, Alexandre Cunha Oliveira ${ }^{2}$, Antônio Marcus Nogueira Lima ${ }^{2}$. \\ 1. GAIC, DECEENG, UNIJUI- Universidade Regional do Noroeste do Estado do Rio Grande do Sul \\ Rua do Comércio, 3000, 98700-000 Bairro Universitário, Ijuí, RS \\ E-mail: camposeunijui.edu.br
}

\author{
2. LEIAM, DEE, UFCG-Universidade federal de Campina Grande \\ Caixa Postal 10105, 58429-900,Bairro Universitário, Campina Grande, PB \\ E-mails: aco@dee.ufcg.edu.br, amnlima@dee.ufcg.edu.br
}

\begin{abstract}
In general electric power systems are susceptible to faults. However high impedance faults still present as a challenge and can not be detected by traditional methods. This paper present a comparison of five techniques for fault detection established in the literature, and compares them in a realistic distribution system. Three scenarios were created and for each of them the techniques chosen were submitted and the results analyzed. Based on these results, we conclude that none of the techniques studied here presents an optimal behavior in relation to the detection of high impedance faults.
\end{abstract}

Keywords - Application of Intelligent Systems in Power Systems, High impedance faults, Comparison of Techniques, Power Distribution Systems, Low Current Faults.

\begin{abstract}
Resumo-De uma forma geral sistemas elétricos de potência estão susceptíveis a falhas. Entretanto faltas de alta impedância se apresentam ainda como um desafio e não podem ser detectadas pelos métodos tradicionais. Este trabalho apresenta a comparação de cinco técnicas de detecção de faltas consagradas na literatura, e as compara em um sistema de distribuição realístico. Foram criados 3 cenários e para cada um deles as técnicas escolhidas foram aplicadas e seus resultados analisados. Com base nos resultados obtidos, podemos concluir que nenhuma das técnicas aqui estudadas apresenta um comportamento ótimo em relação à detecção de faltas de alta impedância.
\end{abstract}

Palavras-chave - Aplicação de Sistemas Inteligentes em Sistemas de Potência, Faltas de Alta impedância, Comparação de Técnicas, Sistemas de Distribuição de Energia Elétrica. Faltas de Baixa Corrente.

\section{Introdução}

De uma forma geral sistemas elétricos de potência estão susceptíveis a falhas. Conforme Tleis (Tleis, 2008), uma falha em um sistema de potência é uma condição anormal, que envolve uma falha elétrica na operação de algum tipo de equipamento, operando em uma das tensões primárias do sistema.

As falhas mais comuns em sistemas de distribuição são a ocorrência de curto-circuito na média e baixa tensão; a queima de transformadores, pela constante ocorrência de curtos; o afrouxamento de conexões que ligam condutores aos demais componentes da rede. Estas falhas são normalmente ocasionadas por: quebra de cabos aéreos, quebra de isoladores, deterioração dos transformadores de distribuição e seus componentes, acúmulo de sujeira sobre os isoladores, atos de vandalismo, fenômenos da natureza (como raios, ventos e queda de árvores ou galhos) e acidentes com viaturas. Tipicamente de $80 \%$ á $90 \%$ das falhas de curto-circuito ocorrem em ramais de distribuição aéreos e o restante em subestações e barramentos (Tleis, 2008).

No Brasil, a distribuição da energia elétrica se faz, quase na sua totalidade, através de ramais aéreos alimentados em tensões na ordem de $15 \mathrm{kV}$ ou $23 \mathrm{kV}$. Os condutores nus presentes nas redes elétricas de distribuição dos centros urbanos, disputam o mesmo espaço com árvores e edificações. A principal vantagem de utilizar este modelo é a redução do custo. A desvantagem mais evidente é a fragilidade deste sistema, exposto a condições adversas, que o leva a ser mais propenso a faltas que o sistema subterrâneo.

Se ocorrer uma falha mecânica em um condutor, no sistema de fixação deste ao poste, ou até mesmo no poste, a população próxima a esta região estará exposta a uma condição de risco de acidentes com potencial de fatalidade elevado. Não se pode esquecer que este modelo foi desenvolvido há 50/60 anos e apresenta, atualmente, saturações tecnológicas, propiciando baixo nível de confiabilidade no sistema elétrico de distribuição de energia.

Durante os últimos anos muitos pesquisadores têm trabalhado para apresentar às concessionárias de energia técnicas que possam identificar, classificar e localizar faltas em Redes de Distribuição de Energia (RDE).

Conforme Zamora, et al. (2007) para as faltas que apresentam um incremento no fluxo de corrente de um sistema, já existem diversos dispositivos de proteção disponíveis. Quanto maior o nível do aumento de corrente do sistema mais fácil é a detecção da falta. Entretanto as faltas de baixa corrente (LowCurrent Faults (LCF)) também conhecidas como faltas de alta impedância (High Impedance Fault (HIF)) se apresentam ainda como um desafio e não podem ser detectadas pelos métodos tradicionais. Estas são faltas cujos valores de corrente, nos alimentadores da distribuição, ficam abaixo dos valores de partida dos relés de sobrecorrentes clássicos. 
As faltas de alta impedância (HIF) se caracterizam na maioria das vezes pelo contato de um condutor energizado em solos de baixa condutividade, galhos de árvores balançando e encostando em uma linhas de transmissão, isoladores poluídos entre outros. Conforme Hou (2006) em diversos estudos realizados a partir de testes preparados para simulação e análise das HIFs dos sistemas de distribuição aterrados, os pesquisadores registraram magnitudes das correntes de falta variando de zero a menos de 100 ampères.

Este trabalho objetiva apresentar a comparação de cinco técnicas consagradas na literatura, e testalas em um sistema de distribuição realístico. Foram criados 3 cenários e para cada um deles as técnicas escolhidas foram aplicadas e seus resultados analisados.

Este trabalho esta organizado da seguinte forma: Na secção 2 é apresentado o sistema de distribuição realístico, bem como as técnicas de detecção de faltas que foram utilizadas; Na 3 secção os cenários definidos para o estudo bem como os resultados obtidos paraa aplicação das técnicas em cada um deles, incluindo uma análise dos resultados. Finalmente na $4 \mathrm{e}$ ultima secção são apresentadas as discussões sobre o trabalho e as propostas de trabalhos futuros.

\section{Sistema de Distribuição e Técnicas de Detecção de Faltas de Alta Impedância}

Em Zamora et al. (2007) é apresentado um sistema de distribuição realístico de Modelos equivalentes de um sistema elétrico de distribuição.

Este sistema realístico foi simulado no $\mathrm{Matlab}^{(\mathrm{R})}$ com algumas alterações para torná-lo mais semelhante ao sistema elétrico típico brasileiro. São elas, a substituição dos ramais subterrâneos por ramais aéreos tornando-se então $44,3 \mathrm{~km}$ de ramais aéreos (onde todos os cabos isolados foram substituídos por cabos de alumínio), e ainda o transformador foi alterado para que fosse considerada com uma relação de transformação de $69 / 13,8 \mathrm{kV}$ mantendo-se a potência de 12 MVA.

$\mathrm{Na}$ literatura, existem diversas técnicas propostas para a detecção de faltas de alta impedância. Para este trabalho foram escolhidas algumas delas para que fosse realizada uma comparação entre o seu desempenho, utilizando como base um modelo de sistema realístico. Para escolha destes métodos, foram utilizados os seguintes critérios, dois deles que apresentam o melhor resultado nos artigos científico numa vasta gama de aplicações (Transformada de Wavelet e Redes Neurais Artificiais), outros dois baseados na facilidade de implementação (Método de componentes de baixa frequência em sequência zero e Método de componentes de baixa frequência em sequência negativa) e um quinto método que é bastante criticado nos artigos que é o método de detecção de faltas através da Transformada de Fourier Janelada.

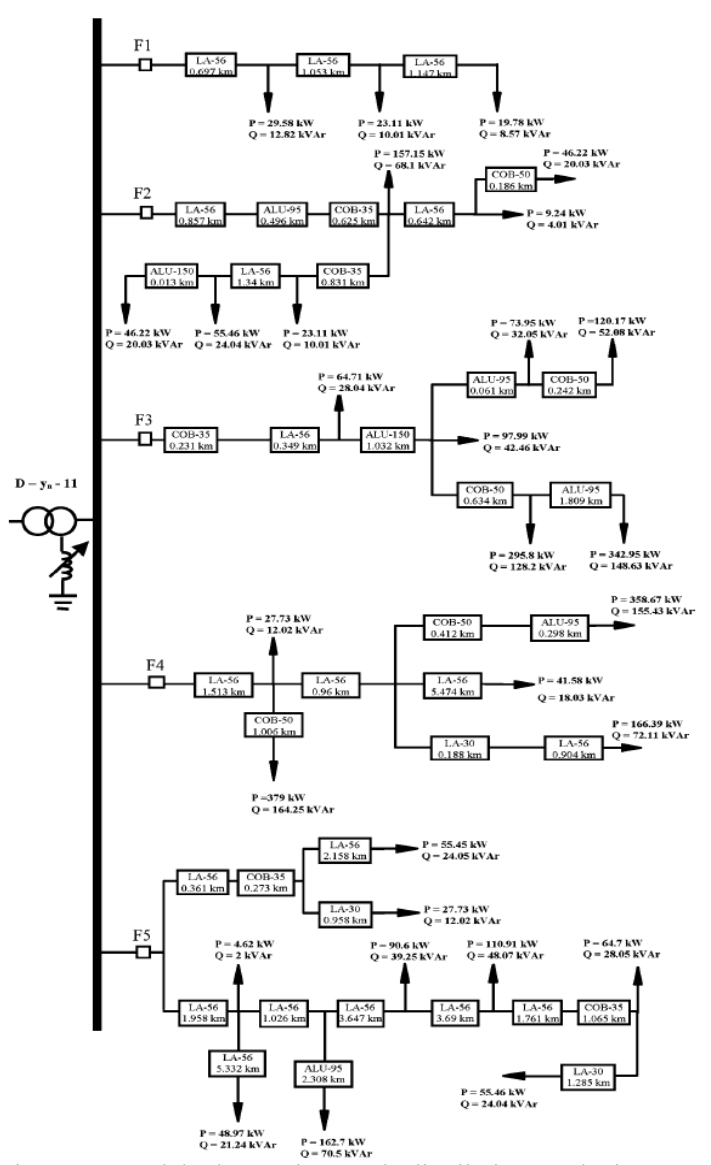

Figura 1 - Modelo de um sistema de distribuição realístico apresentado por Zamora et al. (2007)

\section{Cenários de Testes e Análise dos Resultados}

Para a realização deste estudo, foram criados três cenários. Cada um deles apresenta duas faltas de alta impedância transitórias. Alguns deles ainda apresentam a inserção de eventos comuns do sistema (i.e. banco de capacitores), para verificar a capacidade das técnicas em diferenciar tais eventos de faltas de alta impedância. Em todos os Cenários foi utilizado o sistema apresentado na figura 1.

\subsection{Primeiro Cenário}

No primeiro cenário, foram aplicadas duas faltas de alta impedância distantes da subestação. A primeira no final do ramal 1 próximo a última carga iniciando em 0,6 segundos com duração de 0,1 segundos. A segunda falta no final do ramal 3 iniciando em 1,2 segundos com duração de 0,2 segundos. Ainda, foi adicionado um evento considerado normal ao sistema caracterizando o chaveamento de um banco de capacitores no final do ramal 2 em 1,9 segundos.

Simulando o circuito apresentado temos na Figura 2 as correntes do sistema durante todo o período de simulação. Em regime as correntes normais do sistema têm aproximadamente 133A. A variação de corrente é típica de uma falta de alta impedância com variações na ordem de $0,5 \mathrm{~A}$ ( que representa menos de $0,4 \%$ da corrente nominal). Já o chaveamento do banco de capacitores apresenta variação de corrente 
ainda menor, entretanto pode-se observar um significativo incremento no conteúdo em alta frequência.

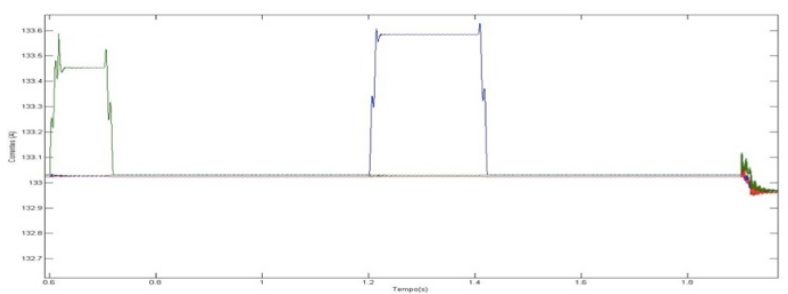

Figura 2 - Correntes RMS do sistema nas condições do cenário 1.

Para este cenário então aplicou-se, a Transformada de Wavelet do tipo Ortogonal com filtro digital FIR (Finite Impulse Response) do tipo Daubechies de Terceira Ordem (db3) produzindo o resultado apresentado na Figura 3.

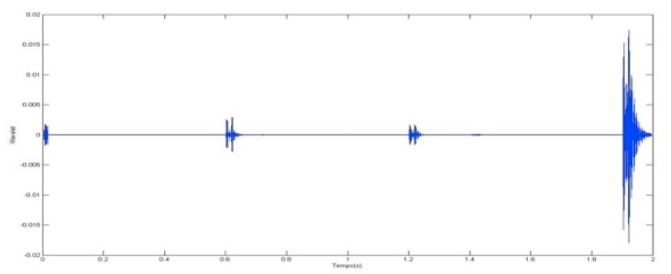

Figura 3 - Resultado da Transformada de Wavelet para cenário 1.

Conforme se pode observar a Transformada de Wavelet consegue perceber o instante inicial de cada uma das faltas. Entretanto o chaveamento de um banco de capacitores é percebido, ainda com mais intensidade e com uma resposta muito semelhante à resposta da WT ao distúrbio característico de uma falta.

Como segundo método proposto, foi empregada a técnica de detecção utilizando uma Rede Neural Artificial (RNA). Neste caso, foi utilizada uma rede com duas camadas (layers) do tipo rede direta (Feedforward). Esta RNA foi treinada utilizando como base os dados deste primeiro cenário. Resposta igual a zero para condição de funcionamento normal e igual a um para detecção de falta. Desta forma, os resultados aqui obtidos (vide Figura 4) são bons, no entanto, devem ser comparados com os resultados obtidos nos cenários seguintes.

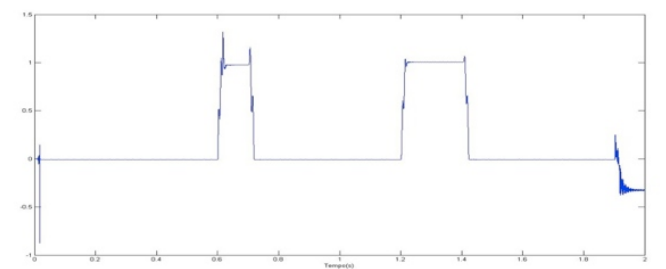

Figura 4 - Aplicação da técnica de RNA no cenário 1.

O terceiro método utilizando Harmônicos não característicos de Sequência Zero foi implementado. Neste caso específico foram analisados os sinais resultantes da segunda harmônica do sistema. Esta é citada na literatura por ser mais imune aos eventos normais do sistema. O resultado desta técnica pode ser observado na Figura 5.

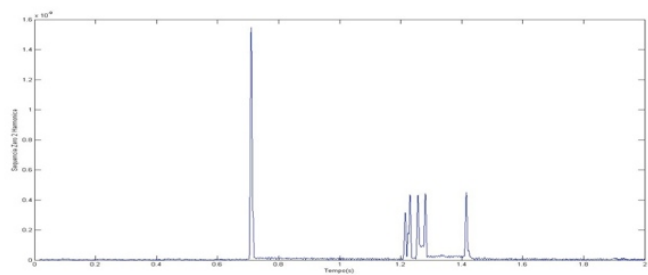

Figura 5 - Harmônicos Não Característicos de Seq. Zerocenário 1.

Pode-se observar que para a primeira falta a técnica é sensível apenas ao instante final da falta, não percebendo seu início. Já a segunda falta é percebida com boa precisão. Ainda, o chaveamento do banco de capacitores não é percebido neste caso.

A técnica que utiliza Harmônicos de baixa ordem de Sequência Negativa para a detecção de faltas de alta impedância foi implementada como o quarto método deste estudo. Na literatura esta técnica é defendida por conseguir perceber variações instantâneas e desbalanços de corrente em um sistema trifásico. Na Figura 6 os resultados desta técnica são apresentados.

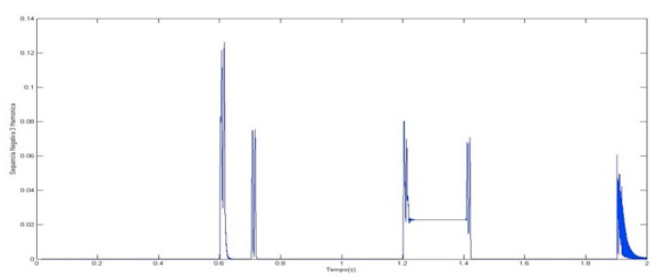

Figura 6 - Harmônicos de baixa ordem de Seq. Negativacenário 1.

Neste caso, a técnica percebeu ambas as faltas, mas foi bastante sensível também para o chaveamento do banco de capacitores.

A última técnica testada foi a Transformada de Fourier Janelada (TFJ), para a implementação desta técnica foram realizadas as seguintes considerações:

Foi encontrada uma componente única que continha o sinal de todas as fases do sistema utilizando a equação:

$$
y(t)=\frac{i a(t)+i b(t)+i c(t)}{(i a(\max )+i b(\max )+i c(\max ))}
$$

Este sinal $\mathrm{y}(\mathrm{t})$ foi amostrado a uma frequência de $20 \mathrm{kHz}$. Utilizando uma janela de Hamming truncada em 256 pontos foi calculado a FFT deste sinal. O resultado desta técnica é apresentado na Figura 7.

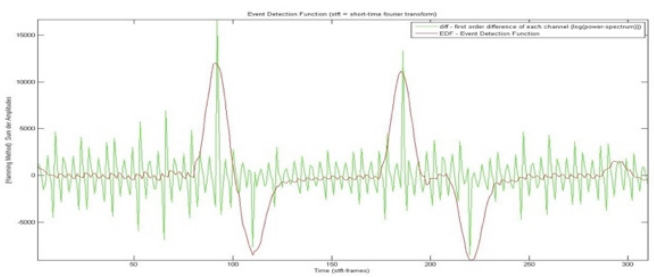

Figura 7 - TFJ utilizando uma janela de Hamming cenário 1.

Como se pode observar esta técnica apresenta uma boa percepção as faltas aplicadas ao sistema, entretanto algumas considerações se fazem necessá- 
rias. Em primeiro lugar o sistema aqui apresentado possui baixa quantidade de ruídos. Em segundo lugar esta técnica necessita do truncamento apresentado no item (c) anterior, este truncamento pode provocar erros quando de faltas que estão fora das frequências vistas por esta janela. Além disso, a informação da janela precisa estar totalmente amostrada para a realização da mesma proporcionando um atraso nesta detecção.

\subsection{Segundo Cenário}

Neste segundo cenário, foram aplicadas três faltas de alta impedância todas distantes da subestação no ramal com corrente de valor significativo em comparação com os demais (ramal 5 têm corrente em torno de $28 \mathrm{~A}$ cerca de aproximadamente $22 \%$ do total) e fases distintas. A primeira iniciando em 0,7 segundos com duração de 0,2 segundos, a segunda iniciando em 1,0 segundo com duração de 0,4 segundos e a terceira iniciando em 1,6 segundos com duração de 0,3 segundos. Foi adicionado também um banco de capacitores em uma posição intermediaria do ramal 1 acionado em 0,2 segundos permanecendo acionado por todo período da simulação.

$\mathrm{Na}$ Figura 8 podemos observar os resultados da aplicação da técnica da Transformada de Wavelet.

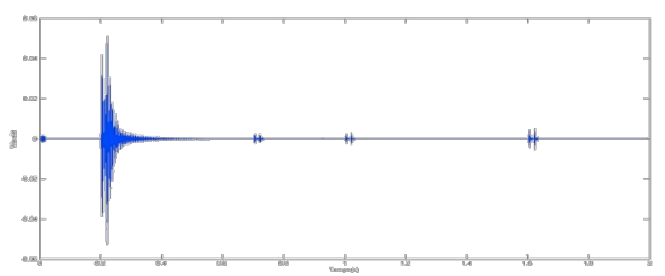

Figura 8 - Resultado da TW para o cenário 2.

O instante inicial de cada uma das faltas é percebido como nos demais casos pela Transformada de Wavelet. Entretanto o distúrbio provocado pelo chaveamento de um banco de capacitores apresenta variações bastante significativas.

Na Figura 9 é apresentado o resultado obtido utilizando a técnica de detecção através de uma Rede Neural Artificial (treinada pelo primeiro cenário). $\mathrm{O}$ que se percebe neste caso é que os valores detectados não convergem para os resultados do treinamento, mesmo assim, as faltas apresentam variações na resposta.

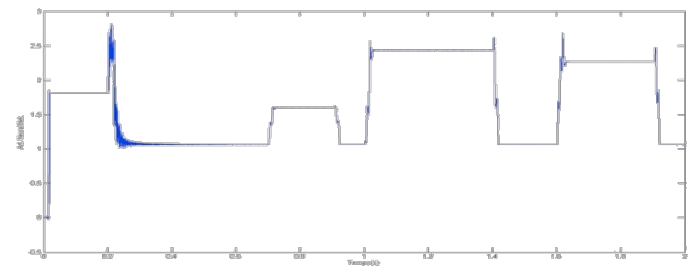

Figura 9 - Resultado da aplicação da RNA no cenário 2.

Na Figura pode ser observado o resultado da implementação do terceiro método para este cenário.

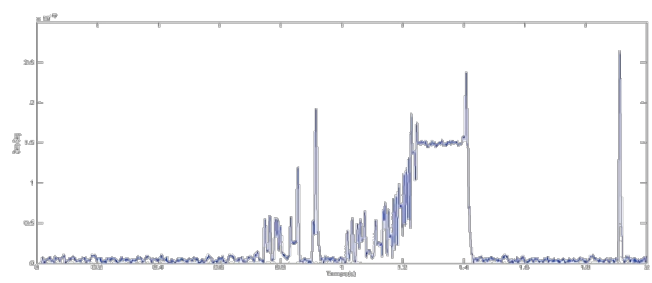

Figura 10 - Harmônicos não característicos Seq. Zero - cenário 2.

Visivelmente, esta técnica para várias condições de falta, consegue apenas perceber o instante final da falta não percebendo que o circuito esta sob condição de falta. Isso pode ser observado novamente na Figura , pois a primeira e a terceira falta apenas são percebidas no instante final da sua ocorrência.

Implementando-se a técnica de análise de terceiro harmônico de Sequência Negativa para este cenário temos os resultados mostrados na Figura 11.

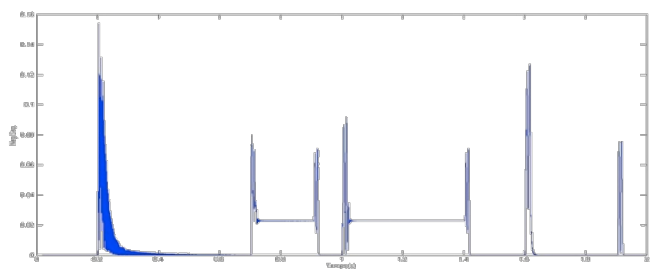

Figura 11 - Harmônicos de baixa ordem Seq. Negativa cenário 2.

Esta técnica neste cenário também percebeu as faltas adequadamente, no entanto como nos demais casos ela foi bastante sensível também para o chaveamento do banco de capacitores.

Como se pode observar na Figura 8 a técnica utilizando a Transformada de Fourier Janelada apresenta uma boa percepção das faltas aplicadas ao sistema. Ainda, também neste caso o banco de capacitores apresentou um distúrbio de menor intensidade mas que foi confundido pela técnica.

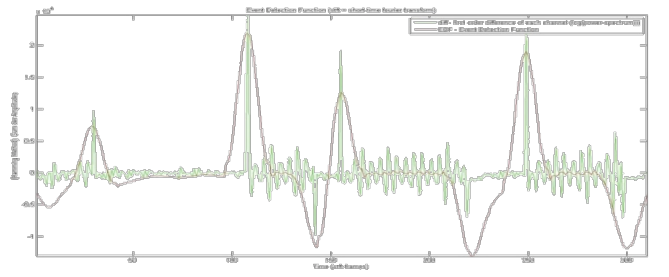

Figura 8 - TFJ utilizando uma janela de Hamming cenário 2.

\subsection{Terceiro Cenário}

Finalmente, neste Terceiro cenário, foram aplicadas duas faltas de alta impedância uma no ramal 1 e outra no ramal 3. A primeira iniciando em 0,6 segundos com duração de 0,1 segundos, a segunda iniciando em 1,2 segundos com duração de 0,2 segundos. Foi adicionado um banco de capacitores no ramal 2 acionado em 1,9 segundos. E ainda, uma variação de carga no ramal 4 do sistema em $1 \mathrm{~s}$. Esta variação é bastante significativa, pois tem um nível de corrente de aproximadamente $15 \mathrm{~A}$ representando $12 \%$ da corrente nominal do sistema completo.

Pode-se observar os resultados da aplicação da técnica da Transformada de Wavelet do tipo Daubechies de Terceira Ordem (db3) no cenário 4 através 
da Figura 9. O instante inicial de cada uma das faltas é percebido, entretanto a variação de carga e o acionamento do banco também apresentam uma assinatura neste sinal. Assim, em todas elas, fica difícil a identificação do evento, considerando apenas esta informação

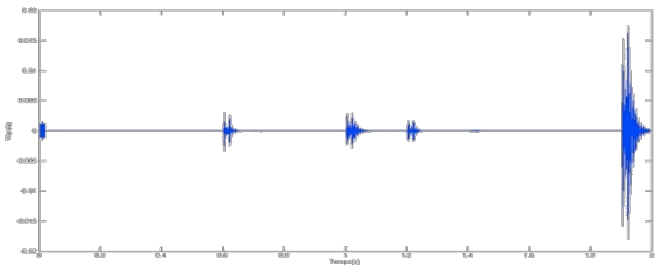

Figura 9 - Resultado da TW para o cenário 3.

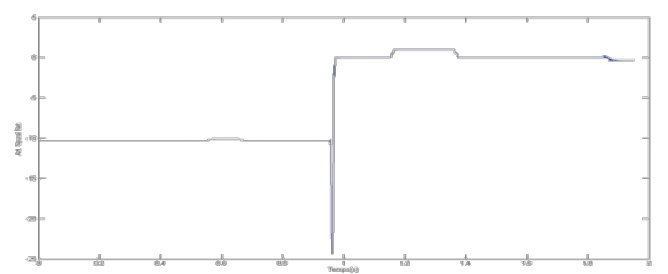

Figura 10 - Resultado da aplicação da técnica RNA no cenário 3.

Utilizando a técnica de detecção através de uma Rede Neural Artificial (treinada a partir das informações geradas pelo primeiro cenário) temos os resultados mostrados na Figura 10. Neste caso os valores detectados também não convergem para os resultados do treinamento, mesmo assim, as faltas apresentam variações na resposta da mesma forma que no cenário 2.

Realizando o re-treinamento da rede neural para este caso específico, obtem-se o resultado apresentando na Figura 15, onde podemos observar que as faltas foram detectadas perfeitamente e os eventos normais do sistema apresentam apenas pequenos transitórios.

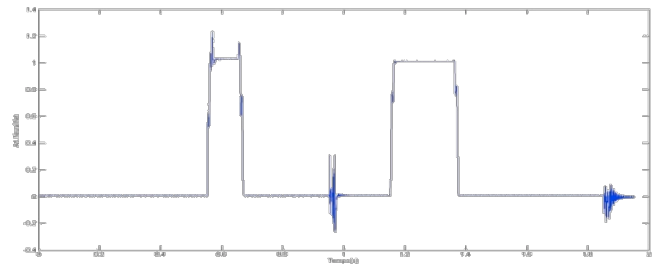

Figura 15 - Resultado do cenário 3 utilizando uma RNA treinada especificamente pra este caso.

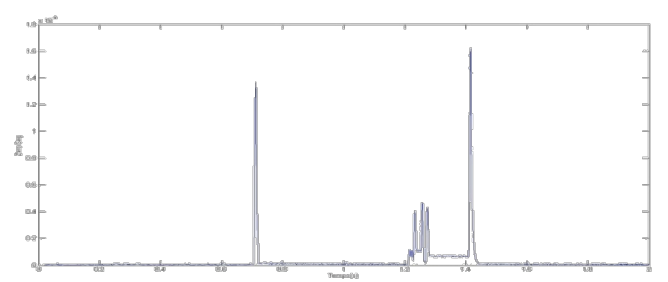

Figura 16 - Harmônicos não característicos Seq. Zero -cenário 3.

Para este quarto cenário pode-se observar o resultado da implementação do terceiro método na Figura . Novamente esta técnica em alguns casos, consegue apenas perceber o instante final da falta não percebendo o início da mesma. O que chama atenção novamente é que nem o banco de capacitores nem a variação de carga foram detectadas por este método.

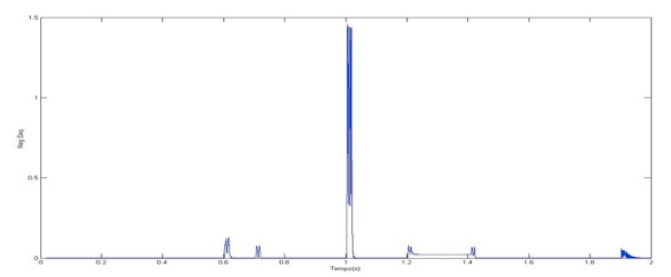

Figura 17 - Harmônicos de baixa ordem Seq. Negativa cenário 3.

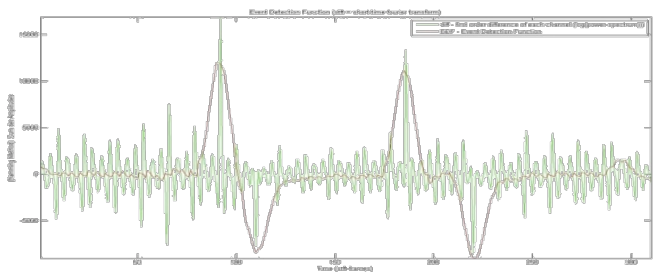

Figura 18 - TFJ utilizando uma janela de Hamming cenário 3.

Na Figura 17 tem-se a implementação da técnica de análise de terceiro harmônico de Sequência Negativa para este cenário. Neste caso, para esta técnica, a variação de carga apresenta um incremento significativo na informação, e ainda, as faltas foram detectadas corretamente. Como nos casos anteriores podemos destacar que todos os eventos do sistema aparecem nesta técnica, sejam eles provenientes de falta ou não.

Finalmente, na Figura 18 pode-se observar para a técnica utilizando a Transformada de Fourier Janelada que se tem uma boa percepção das faltas aplicadas ao sistema.

\section{Conclusões}

Neste trabalho foram definidos 3 cenários diferentes de possíveis faltas e eventos normais que podem ocorrer em um sistema de distribuição de energia elétrica. Com base nos resultados obtidos, podemos concluir que nenhuma das técnicas aqui estudadas apresenta um comportamento ótimo em relação à detecção de faltas de alta impedância. Entretanto, varias ponderações podem ser feitas neste momento.

A Transformada de Wavelet é bastante sensível aos eventos transitórios do sistema. Assim, ela consegue perceber toda e qualquer condição de falta do sistema. Entretanto, operações normais como, variações abruptas de carga e chaveamento de bancos de capacitores, também são vistas por ela como eventos no sistema e apresentam resultados muito semelhantes. Mesmo assim, a condição de percepção em $100 \%$ dos casos de falhas por esta técnica não pode ser desprezada.

A conclusão parcial que podemos chegar sobre a técnica baseada em Redes Neurais Artificiais é que se esta for corretamente treinada, possui entre todas, o melhor desempenho para o reconhecimento de padrões específicos no sistema. No entanto, a previ- 
são de todos os eventos normais do sistema, bem como, as perturbações de carga específicas que podem acontecer no mesmo, são impossíveis de ser modeladas. Assim, o treinamento da rede neural é fator decisivo para o bom desempenho da mesma.

Em todos os cenários, a técnica baseada em Harmônicos não característicos de Sequência Zero (neste caso específico foram observados os Harmônicos de segunda ordem), demonstrou falhas na detecção de faltas de alta impedância. Principalmente, na detecção do início da falta, o que ocorreu em condições de falta distintas e aleatórias. Assim, esta técnica não apresenta confiabilidade, para este tipo de detecção. Por outro lado, se observarmos em todos os casos aqui estudados, os eventos ditos normais do sistema, não foram na sua totalidade detectados. Ou seja, apesar de não detectar com precisão as Faltas de Alta impedância, esta técnica consegue ser imune (ao menos nos casos aqui estudados) aos eventos normais do sistema.

Para a técnica baseada na observação dos Harmônicos de baixa ordem de Sequência Negativa, podemos concluir que a mesma possui um desempenho limitado. Principalmente, se levarmos em conta que todos os eventos do sistema interferem neste sinal tornando quase impossível determinar uma falta neste caso. Ainda pode-se observar no cenário de número três que qualquer ruído no sistema altera ainda mais o desempenho desta técnica.

Finalmente, a técnica baseada na Transformada de Fourier Janelada, apresentou um bom desempenho. Entretanto como já foi afirmado o sistema avaliado possui baixa quantidade de ruídos, o truncamento necessário para o cálculo pode provocar erros ou inclusive a não percepção de uma falta.

Uma avaliação, verificando mecanismos de combinação das técnicas apresentadas, se apresenta como um estudo que pode contribuir no sentido de se propor um mecanismo mais eficiente na detecção das faltas de alta impedância.

\section{Agradecimentos}

Agradecimento ao programa Pró engenharias da CAPES, AO LEIAM/UFCG e ao GAIC/UNIJUI.

\section{Referências Bibliográficas}

Aucoin, B. and Jones, R., "High Impedance Detection Implementation Issues." IEEE Transactions on Power Delivery. January 1996, Vol. 11, Issue: 1, pp. 589-594.

Ebron, Sonja, Lubkeman, David L. and White, Mark., "Neural Network Approach to the Detection of Incipient Faults on Power Distribution Feeders." IEEE Transactions on
Power Delivery. Issue: 2, April 1990, Vol. 5, pp. 905-914.

Filho, E. L. M. (1992). Manual de Redação e Estilo, Maltese.

Huang, H. S. and Lu, C. N (1994). Efficient Storage Scheme and Algorithms for W-matrix Vector Multiplication on Vector Computers. IEEE Transactions on Power Systems, Vol.9, No. 2; pp. 1083- 1094. DOI: 10.1109/59.317622

Karimi, Masoud, Mokhtari, Hossein and Iravani, M. Reza., "Wavelet Based On-Line Disturbance Detection for Power Quality Applications." IEEE Transactions on Power Delivery. Issue 4, October 2000, Vol. 5, pp. 1212-1220.

Kostenko, M. and Piotrovsky, 1970, L., Electrical Machines, part 2, Mir, Russia.

Li, L. and Redfem, M.A., "A Review of Techniques to Detect Downed Conductors in Overhead Distribution Systems." [ed.] IEE. Amsterdan : s.n., 2001. Developments in Power System Protection, 2001, Seventh International Conference on (IEE) . pp. 169-172.

Lin, S.L. and Van Ness J.E (1994). Parallel Solution of Sparse Algebraic Equations. IEEE Transactions on Power Systems, Vol.9, No. 2, pp. 743799. DOI: $10.1109 / 59.317666$

Marquadt, D.W., June 1963, "An Algorithm for Least-squares Estimation of Nonlinear Parameter" - J. Soc. Indust. Appl. Math., vol. 11, n ${ }^{\circ}$, pp. 431-441. DOI: 10.1137/0111030

Monticelli, A. (1983). Fluxo de Carga em Redes de Energia Elétrica. Edgar Blucher, Rio de Janeiro RJ.

Morelato, A; Amaro, M. and Kokai,Y (1994). Combining Direct and Inverse Factors for Solving Sparse Network Equations in Parallel. IEEE Transactions on Power Systems, Vol. 9, No. 4, pp. 1942-1948. DOI: 10.1109/59.331454

Robertson, David C., et al., "Wavelets and Electromagnetic Power System Transients." IEEE Transactions on Power Delivery. Issue 2, April 1996, Vol. 11, pp. 1050-1058. DOI: $10.1109 / 61.489367$

Tleis, Nasser Dib., Power Systems Modelling and Fault Analysis - Theory and Practice. Oxford : Elsevier Ltd., 2008. p. 650. 978-0-7506-8074-5.

Xiangjun, Zeng, et al., "Novel Techniques for Earth Fault Feeder Detection Based on Negative Sequence Current in Industry Power Systems." Chicago, IL, EUA : s.n., 2001. Industry Applications Conference, 2001. 36a. IAS Annual Meeting. Vol. 3 , pp. 1831 - 1837.

Zamora, I., Mazón, A. J., Sagastabeitia K. J. And Zamora J. "New Method for Detecting Low Current Faults in Electrical Distribution Systems." IEEE Transactions on Power Delivery. October 2007, Vol. 22, Issue: 4, pp. 2072. DOI: 10.1109/TPWRD.2007.905273 